\title{
Metabolomics based on UHPLC-QToF- and APGC-QToF-MS reveals metabolic pathways reprogramming in response to tidal cycles in the sub-littoral species Mimachlamys varia exposed to aerial emergence
}

\author{
Ory Pascaline ${ }^{1}$, Bonnet Antoine ${ }^{1}$, Mondeguer Florence ${ }^{2}$, Breitwieser Marine ${ }^{1}$, Dubillot Emmanuel ${ }^{1}$, \\ Graber Marianne ${ }^{1,{ }^{*}}$
}

\footnotetext{
${ }^{1}$ Littoral Environnement et Sociétés (LIENSs), UMR 7266, CNRS-Université de La Rochelle, 2 rue Olympe de Gouges, F-17042 La Rochelle Cedex 01, France

${ }^{2}$ Ifremer, Laboratoire Phycotoxines, Rue de l'lle d'Yeu, 44311 Nantes Cedex, France

* Corresponding author : Marianne Graber, email address : mgraber@univ-Ir.fr
}

\begin{abstract}
:
Mimachlamys varia is a sub-littoral bivalve encountered from Norway to the Mediterranean Sea, which lives mostly byssally attached to rocks. During the low tide period, $M$. varia individuals, located highest on the shore, may experience short time of aerial exposure and face a low availability of oxygen. Here we report a comparative metabolomic profiling of gill samples of $M$. varia obtained by both LC-QToF and APGC-QToF mass spectrometry, to analyze metabolic changes occurring during emersion in comparison with immersion. Scallops were grown in aquaria with a simulated intertidal environment mimicking short-duration air exposure that they might experience during extreme tides: alternating $2 \mathrm{~h}$ emersion and $10 \mathrm{~h}$ immersion. Our results show a switch from aerobic to anaerobic metabolism after only $2 \mathrm{~h}$ of emersion, with the resort to different pathways: glucose-lactate, glucose-succinate and aspartate-succinate pathways. Furthermore, carnitine-conjugated metabolites were found to accumulate during emersion, as well as urate. The level of tyrosine on the contrary was found to decrease. These findings indicate a complex metabolic reprogramming that occurs after a two hour emersion period and upon re-immersion. Furthermore, $M$. varia is used as sentinel species in pollution biomonitoring, through the assay of biomarkers to evaluate the effects of pollutants. Here we show that emersion induces a significant decrease of superoxide dismutase activity, an enzyme developed by bivalves to face oxidative stress and used as biomarker. These findings have to be taken into account to normalize sampling during campaigns of environmental monitoring, by taking in situ, as far as possible only immersed individuals.
\end{abstract}

Keywords: Anaerobic, APGC-QToF mass spectrometry, Hypoxia, Intertidal, LC-QToF mass spectrometry, Metabolomics, Mimachlamys varia, PLS-DA 


\section{Introduction}

Mimachlamys varia, commonly known as the variegated scallop, is a marine bivalve in the family Pectinidae. It has a wide distribution from southern Norway, along the western coasts of the British Isles, France, and the Iberian Peninsula and throughout most of the Mediterranean Sea (Shumway and Parsons, 2016). This sub-littoral species occurs at depths ranging from very low intertidal to $100 \mathrm{~m}$. It is mostly byssally attached to rocks or among rough ground or more rarely free-living (Duncan et al., 2016). During the low tide period, $M$. varia individuals attached in the low intertidal area, but located at the highest positions on the shore, may experience short time of aerial exposure. During this period of emersion, they have to face a low availability of dissolved oxygen, as they have only a small reserve of seawater inside their two-part shells. Contrary to oysters and mussels, variegated scallops are unable to remain tightly closed for extended periods of time. In the absence of danger, their shells are therefore usually held slightly open, whether they are in or out of the water. This raises several questions: is the dissolved oxygen in the seawater inside the shells sufficient to allow for breathing during this short period of emersion? Is the air breathing capacity of scallops sufficient to maintain aerobic metabolic pathways? Little is known about the air-breathing capacity of scallops upon emersion (Shumway and Parsons, 2016), nor about their ability to shift towards an anaerobic metabolism during the short emersion periods they undergo. This resort to anaerobic energy production is common among intertidal bivalves upon emersion. Indeed, they cannot meet their oxygen requirements in air, due to inadequate gas uptake or delivery mechanisms and the danger of desiccation when exposing moist surface. The result is that many inhabitants of the marine intertidal area, such as mussels and oysters, undergo a number of physiological and metabolic changes associated with alternating periods of immersion and emersion. These changes include a shift from aerobic to anaerobic metabolism, as scallops close shell valves to prevent desiccation and are subjected to a sharp decrease of dissolved oxygen availability (Akberali and Trueman, 1985; Connor and Gracey, 2012; De Zwaan and Wijsman, 1976; Dudognon et al., 2013; Isani et al., 1995; Shick et al., 1986). The aim of this paper is thus to provide a global insight into the metabolic changes occurring during short aerial emergence in comparison with periods of immersion, for the particular species Mimachlamys varia. This will help in a better understanding of physiological processes in scallops upon emersion.

In addition to providing insight into this physiological aspect for Mimachlamys varia, this study may contribute meaningfully to improve ecotoxicological studies using this same marine organism. Indeed, 
due to its relative abundance along the coasts and also because this species has been shown to have a very elevated pollutants incorporation and retention capacity, it has been proposed as a potential ecotoxicological biomonitoring species for the marine environmental watch (Metian et al., 2009a, 2009b; Milinkovitch et al., 2015). However, during campaigns of environmental monitoring using $M$. varia as sentinel species, samples of these scallops are taken in situ on the shore at low tide at high tidal coefficient, indifferently emerged or still immerged and biomarkers are assayed to evaluate the sub-lethal effects of pollutants (Breitwieser et al., 2018, 2016). In order to provide normalized sampling methods, during environmental biomonitoring using biomarkers in $M$. varia, it is important to exactly know how metabolism of $M$. varia individuals living in the low intertidal is modified during emersion period. Indeed these metabolic changes are likely to lead to confounding factors and to increase the variability of biomarker responses. For example, it was shown that hypoxia induced tissue-specific responses in both antioxidant and immune systems in mussels (Nogueira et al., 2017).

In order to reveal new insight into the metabolic adaptations to emersion of $M$. varia, we grew scallops in aquaria with a simulated intertidal environment and a metabolomics study was performed during six complete tidal cycles. These experimental conditions were chosen to mimic short-duration air exposure that might be experienced by variegated scallops, located highest on the foreshore, during extreme spring and autumn tides: alternating $2 \mathrm{~h}$ air exposure and $10 \mathrm{~h}$ immersion. A comparative metabolomics study was performed in gills samples, using both LC-QToF and APGC-QToF mass spectrometry, in order to provide a temporal overview of the relationship between tidal cycles and metabolome changes. Besides the effect of these tidal cycles on metabolome, the variation of SOD (superoxide dismutase) activity was measured all along the experiment. This enzyme is a part of the enzymatic antioxidant system developed by bivalves to face oxidative stress. It is considered as a precocious biomarker linked to this particular stress (Valavanidis et al., 2006) and it is used to monitor and evaluate the possible health impairment in marine organisms, following for example acute or chronic pollution (Breitwieser et al., 2018, 2016).

\section{Materials and Methods}

\section{Animals and experimental design}

M. varia of 4 to $5 \mathrm{~cm}$ length were collected in the Pertuis Charentais (France) in December 2016. They were then maintained in six 15-litre aquaria in the laboratory at a constant temperature of $15^{\circ} \mathrm{C}$. Food as liquid algal culture (Shellfish Diet $1800^{\circledR}$, Reed Mariculture, Campbell, CA, USA) was added to the water. The commercial liquid feed was diluted before use to contain 1 million cells per $\mathrm{ml} .1 \mathrm{ml}$ per aquarium was added every two days. Intertidal conditions were simulated using water pumps that filled and emptied the aquaria with natural seawater, taken close to Loix-en-Ré, on the north coast of 
the island of Ré (France). This seawater was filtered through a $50 \mu \mathrm{m}$ filter and submitted to UV treatment immediately prior to use. Once a day, at the end of low tide period, the seawater was totally replaced by filling the aquaria with fresh seawater. A tidal regime of alternating periods of $10 \mathrm{~h}$ in and $2 \mathrm{~h}$ out of seawater was established. This last duration corresponds to a maximal emersion time endured by M. varia individuals living in the low intertidal area. Low tides occurred from 8:30 to 10:30 A.M. and 8:30 to 10:30 PM. A light-dark cycle was also programmed with periods of darkness occurring from 8:00 PM to 8:00 AM (Figure 1). 150 individuals of scallops (25 per aquarium) were acclimated during four weeks to alternating high and low tides, before sampling. The percentage of mortality during this acclimatization and study period respectively were equal to $2.7 \%$ and $1.3 \%$. Samples were collected $0.25 \mathrm{~h}$ before the change in tidal episode (at 8:15 AM, 10:15 AM, 8:15 PM and 10:15 PM) during 3 days corresponding to 6 total tidal cycles. The first sampling occurred at 8:15 AM. Nine individual scallops were collected at each time point in different aquaria. On the whole, 108 individuals were used for the experiment. Immediately after sampling, gill tissue was dissected from each individual, drained on absorbent paper and put in cryovial on ice. Gill tissues from three individuals were pooled, snap-frozen in liquid nitrogen and stored in liquid nitrogen. During the whole periods of acclimatization and study, $\mathrm{pH}, \mathrm{O}_{2}$, temperature and salinity were monitored every day and the level of nitrites, nitrates and ammonia every 2 days and did not show any change likely to affect the metabolomics study.

\section{Total protein concentration and SOD activity: sample processing and assays}

For each pool of three individuals, $100 \mathrm{mg}$ of gills were collected after dissection and mixing. They were then homogenized in ice-cold phosphate buffer (100 mM, pH 7.2, $1100 \mathrm{mOsm})$. The homogenates were centrifuged at $12,500 \mathrm{~g}$ at $4{ }^{\circ} \mathrm{C}$ for $15 \mathrm{~min}$ and the supernatants were used for protein and SOD activity assays.

Total protein concentrations were determined using an adaptation of the BCA Kit method (Bicinchononique Acid Kit, Sigma Aldrich). The kit contained bovine serum albumin (BSA) as a standard and involved the reduction of alkaline $\mathrm{Cu}^{2+}$ by proteins (Smith et al., 1985) at absorbance 562 nm using a spectrofluorometer (SAFAS Flx-Xenius).

SOD activity was assessed in the homogenate fractions using the method developed by Paoletti et al. (1986). The assay, involving EDTA, $\mathrm{MnCl}_{2}$ and mercaptoethanol, measures the decrease of nicotinamide adenine dinucleotide (NADH) oxidation. This inhibition of oxidation was monitored at $340 \mathrm{~nm}$ (using SAFAS Flx-Xenius spectrofluorimeter) and is a function of SOD activity. Fifty percent inhibition of oxidation corresponds to one unit of SOD. The results are presented in UI of SOD/mg of proteins. Statistical analyses were carried out using R language (v. 3.1.2, R Core Team, 2016). Normality was first tested on residuals using Kolmogorov-Smirnov tests and homogeneity of variances was assessed using Bartlett tests. For SOD values, tides (low and high) were compared at two times per day for each day, using One-Sample t-tests. 


\section{Sample preparation for metabolomics study}

The efficiency of the following technique, inspired by a metabolomics study in Phycotoxines laboratory (Ifremer, Nantes, France), has previously been established (Mondeguer et al., 2015). Samples were thawed on ice, homogenized by manual grinding with a mini pestle and then crushed with a homogenizer T 10 basic Ultra-Turrax (IKA®-Werke GmbH \& Co. KG, Germany) at low speed. Each sample was precisely adjusted to $1 \mathrm{~g}$ and $100 \mathrm{mg}$ of homogenized sample were also put aside in a separate tube in order to perform SOD activity measurement. Tubes were then stored at $80^{\circ} \mathrm{C}$ for one night before extraction procedure.

Samples were then subjected to a triple solvent extraction protocol by successively using acetone twice and methanol. For each extraction, the following protocol was used: addition of $2.5 \mathrm{~mL}$ of solvent to the sample, resuspension and dispersion with homogenizer $\mathrm{T} 10$ basic Ultra-Turrax, agitation $140 \mathrm{rpm} 10$ minutes, centrifugation at $3000 \mathrm{~g}$ during 5 minutes, removal of supernatant. Ultra-Turrax was rinsed in the solvent of the next step. The three supernatants were then pooled, put at $4^{\circ} \mathrm{C}$ and subjected to centrifugation at $3000 \mathrm{~g}$ during 5 minutes. The supernatant was recovered and dried with a stream of nitrogen at $30^{\circ} \mathrm{C}$ until reduction of the volume to $50 \%$ and at $50^{\circ} \mathrm{C}$ until complete drying. The dry extract was finally re-suspended with $2 \mathrm{~mL}$ methanol/water 20/80 and stored at $-80^{\circ} \mathrm{C}$ prior filtration with $0.2 \mu \mathrm{m}$ filters and LCMS analysis.

\section{LC-QToF MS analysis of metabolites}

The analysis of metabolite compounds in gills was performed by ultra-high performance liquid chromatography coupled to high resolution mass spectrometry (UHPLC-HRMS). Analyses were carried out using an UHPLC system "Acquity UPLC H-class" (Waters, Milford, USA) coupled to a high resolution mass spectrometer "XEVO-G2-S Q-TOF" equipped with an electrospray ionization source (Waters, Manchester, England). The UHPLC system was formed by a quaternary pump (Quaternary Solvent Manager, Waters) and an automatic injector (Sample Manager-FTN, Waters) equipped with a $10 \mu \mathrm{L}$ injection loop. $5 \mu \mathrm{L}$ of the samples were injected in a column "Acquity UPLC HSST3" (Waters) $(2.1 \times 150 \mathrm{~mm}, 1.7 \mu \mathrm{m})$, and the products were eluted at a flow rate of $200 \mu \mathrm{L} . \mathrm{min}^{-1}$ using a gradient composed of solvents A (water/formic acid 100/0.001 (v:v)) and B (acetonitrile/ formic acid 100/0.001 (v:v)), according to the following procedure: 0-3 min, 100\% A; 3-8 min 0\%$50 \%$ B ; 8-13 min 50\% B; 13-20 min 50-95\% B; 20-30 min, 95\% B, 30-31 min 95-0\% B, 31-36 min $100 \% \mathrm{~B}$. During the analysis, the column and the injector were maintained at $25^{\circ} \mathrm{C}$ and $7^{\circ} \mathrm{C}$, respectively. The analyses were performed in positive and negative ionization mode with MS function in a centroid mode. The MS parameters was applied in the ESI source for the two ionization mode were: source temperature $120^{\circ} \mathrm{C}$, desolvation temperature $500^{\circ} \mathrm{C}$, gas flow-rate of the cone $50 \mathrm{~L} \cdot \mathrm{h}^{-1}$, desolvation gas flow-rate $800 \mathrm{~L}^{-1} \mathrm{~h}^{-1}$, capillary voltage $2.5 \mathrm{kV}$, sampling cone $130 \mathrm{~V}$ and source 
compensation $80 \mathrm{~V}$. The instrument was adjusted for the acquisition on a 50-2100 m/z interval, with a scan time of $0.15 \mathrm{~s}$.

The mass spectrometer was calibrated before analysis using $0.5 \mathrm{mM}$ sodium formiate solution and the Leucine Enkephalin $\left(\mathrm{M}=555.62 \mathrm{Da}, 1 \mathrm{ng} . \mu \mathrm{L}^{-1}\right)$ was used as a lock-mass.

Compound identification was performed by matching to a database of authentic compound standards. Metabolites were finally expressed in relative abundance, which was calculated for each metabolite by dividing the abundance in each sample by the median abundance across all the samples.

\section{Quality Control}

A pool sample was prepared by combining $100 \mu \mathrm{L}$ of each gills tissue extract. The pool sample was divided into several vials that were used as quality-control samples (QCs) and regularly injected within samples (one injection every five samples) to ensure analytical repeatability. Samples of gills tissues extracts were measured in randomized order to avoid any possible time-dependent changes in LC/MS analysis. Blanks were prepared with the last extraction solvent and injected at the beginning and at the end of the samples sequence. These blanks allowed the subsequent subtraction of contaminants or components coming from the extraction solvent.

\section{Chemicals}

Acetonitrile, Methanol, Acetone with HPLC grade purity were acquired from Carlo Erba. Water was prepared using a Milli-Q reagent water system. Succinate, malate, uric acid, aspartate, alanine, citrate, glutamate, propionylcarnitine, isovalerylcarnitine, isobutyrylcarnitine were purchased from SigmaAldrich.

\section{Sample and standards preparation for APGC-QToF MS}

$20 \mu \mathrm{L}$ of samples prepared for metabolomics studies as described above and QC of $10 \mathrm{ng} \mu \mathrm{L}^{-1}$ standard solutions were dried under nitrogen at $40^{\circ} \mathrm{C}$ in vials without inserts. For methoxinationtrimethylsilylation (MeOx-TMS), $20 \mu \mathrm{L}$ of a $20 \mathrm{mg} \mathrm{mL}^{-1}$ methoxylamine hydrochloride in pyridine solution were added to dissolve the dried extract. The vials were then vortex mixed for $15 \mathrm{~s}$ and heated at $80^{\circ} \mathrm{C}$ for $15 \mathrm{~min}$ in derivatization block. Vials were then removed from the block and $20 \mu \mathrm{L}$ of MSTFA (N-methyl-N-(trimethylsilyl trifluoroacetamide)) was added to the samples and QC, vortex mixed for $15 \mathrm{~s}$ again and heated at $80^{\circ} \mathrm{C}$ for $15 \mathrm{~min}$ in the block. Vials were removed from the block and allowed to cool for $5 \mathrm{~min}$. They were then centrifuged at $328 \mathrm{~g}$ for $5 \mathrm{~min}$. Supernatants were transferred to autosampler vials using pipet with filter tips. 
Analyses were carried out using an Agilent GC 7890A (Agilent Technologies, Santa Clara, CA) coupled to a Waters Synapt G2-S ToF (Waters Corporation, Manchester, UK), equipped with APGC (atmospheric pressure gas chromatography) ionization. A DB5-MS (Agilent Technologies) analytical column $(30 \mathrm{~m} \times 0.25 \mathrm{~mm}$ i.d. $\mathrm{x} 0.25 \mu \mathrm{m}$ film thickness consisting of $5 \%$ phényl-diméthylpolysiloxane) was used. The carrier gas was helium; it was used at constant flow equal to $1 \mathrm{~mL} \mathrm{~min}{ }^{-1}$. The temperature program for the gas chromatography was as follows: initial temperature $120^{\circ} \mathrm{C}$ for 0.5 min, increase of temperature by two different rates: $8^{\circ} \mathrm{C} \cdot \mathrm{min}^{-1}$ up to $280^{\circ} \mathrm{C}$ at $22 \mathrm{~min}$ and $20^{\circ} \mathrm{C} \cdot \mathrm{min}^{-1}$ up to $300^{\circ} \mathrm{C}$, then temperature was held at $300{ }^{\circ} \mathrm{C}$ for $5 \mathrm{~min}$. Total time for analysis was $28 \mathrm{~min}$. The injector temperature was $250^{\circ} \mathrm{C}$. Injection was performed in the split mode (1/50) and the injection volume was $2 \mu \mathrm{L}$. The parameters for APGC were: dry mode, corona current $1.3 \mu \mathrm{A}$, probe temperature $20^{\circ} \mathrm{C}$, source temperature $150^{\circ} \mathrm{C}$, sampling cone $30 \mathrm{~V}$ (different sampling cone voltages (from 10 to 40 $\mathrm{V}$ ) were tested and $30 \mathrm{~V}$ was retained), source offset $80 \mathrm{~V}$, cone gas flow $170 \mathrm{~L} / \mathrm{Hr}$, auxillary gas flow $220 \mathrm{~L} / \mathrm{Hr}$. The instrument was adjusted for the acquisition on a $50-700 \mathrm{~m} / \mathrm{z}$ interval, with a scan time of $0.5 \mathrm{~s}$. The instrument was calibrated by Heptacosa (perfluorotributylamine mixture) to ensure mass accuracy. During acquisition, the column bleeding ion $281.0517 \mathrm{~m} / \mathrm{z}$ was used as lockmass.

\section{Statistical analysis}

Data were obtained and treated as ion peak intensity after conversion of raw spectra (.RAW) to .NetCDF format, compatible with Galaxy software, using "Databridge" software (Waters). Metabolites data were pre-processed on the online and freely available Workflow4Metabolomics (W4M) platform (http://workflow4metabolomics.org) for data pretreatments. Parameters used for pre-

processing are available at lis https://galaxy.workflow4metabolomics.org/u/abonnet/w/preprocess-workflow. Batch correction was applied to eliminate instrument signal drift and offset differences between batches. Sample intensities were adjusted using a Lowess regression model fitting with the pool values (Van Der Kloet et al., 2009). Quality metrics tool provided visualization of the data matrices and supplied a rapid highlight of QC sample drift and potential sample outliers. These outliers were subsequently confirmed with the multiple analysis process and discarded according to these results for further data processing.

We evaluated the analytical repeatability of metabolite intensity dataset by calculating coefficients of variation $(\mathrm{CV})$ detected in the QC samples. Metabolites with $\mathrm{CV}>0.4$ were removed from the datasets for the entire analyses.

A set of generic filters allowed to remove qualitatively blanks and QC samples and/or quantitatively variables corresponding to specific values regarding designated factors or numerical variables (for $\mathrm{CV}$ selection for example). After pretreatment, data were analyzed with the web server MetaboAnalyst 4.0 (www.metaboanalyst.ca) for multivariate analyses processing: the data were normalized by logtransformation, and Pareto scaling was applied prior to multivariate analyses to adjust the potential large different ranges observed between variables. The data were analyzed using both unsupervised 
(Principal Component Analysis, PCA) and supervised (Projections to Latent Structures Discriminant Analysis, PLS-DA) methods. Unsupervised method allowed detecting general spectral trends and natural clustering between samples justifying the PLS-DA model reliability. It also highlighted the potential sample outliers. The supervised method is a multivariate regression and prediction based on the separation between two classes: high and low tide samples. It was used to select the metabolites involved in the class separation in order to identify metabolites with a tidal rhythmic pattern. Selection of metabolites was based on the importance of their contribution as variable in the component prediction in PLS-DA model, described as Variable Importance in Projection parameter (VIP). A variable with a VIP-value > 1 can be considered as a metabolite providing a significant contribution to the PLS-DA model.

Predictability performance was evaluated for each built PLS-DA model, using cross-validation method (10-fold CV). To assess the statistical significance, t-tests were performed on each metabolite intensities difference between low tide samples and high tide samples. Normality and homoscedasticity were previously checked.

\section{Identification and relative level of metabolites}

The identification of metabolites, in case of LC-MS analyses, was performed by using the human metabolome database (http://www.hmdb.ca). A research was performed with the mass value of metabolites and a limit with a mass error lower 5ppm. Moreover, corresponding analytical standards were used with the LC-MS method to verify this identification.

The characterization of compound present in case of APGC analyses depends on the chemical reaction used for derivatization. Golm Metabolome Database (http://gmd.mpimp-golm.mpg.de) and the supplementary data of the paper of Jaeger et al. (2016) were used to identify metabolites of interest in APGC. In APGC mode, ion fragmentation frequently occurs, making it possible to identify compounds through their fragments.

Relative metabolite levels were expressed in relative abundance obtained by dividing each metabolite intensity by the median intensity of the same metabolite across all the samples.

\section{Results}

\section{Data processing}

Mass spectrometry untreated analyses detected $9105 \mathrm{~m} / \mathrm{z}$ features for negative ionization mode results in LCMS, 3087 for positive ionization mode and 5426 for APGC results. These large sets of data obtained for metabolomic profiling were preprocessed. After preprocessing and removal of metabolites with high CV, the database of metabolites had 1715, 243 and 709 compounds detected 
with negative and positive ionization modes in LCMS and APGC respectively. They were analyzed to highlight a potential rhythmic pattern of their intensities.

\section{PCA Analysis}

PCA was performed as a first-pass method to confirm metabolite composition differences between tide levels and detect eventual outlier samples. The score plots of PCA analysis are shown in Figure 2. Each point represented an individual sample, and the scatter of points indicated the similarities or differences of metabolic compositions. Samples having similar metabolite contents are clustered together, whereas those having different metabolites are dispersed. The PCA performed with datasets from both low and high tides showed that two groups were well separated according to tidal level for LC-MS in negative mode and APGC. In case of LC-MS in positive mode, there is an observed trend towards separation between the two groups. Thus, compound intensities, considered as variables, contributed to the separated structure observed between high and low tide samples. The two first axes accounted for $24.6 \%-40.5 \%-33.7 \%$ and $18.5 \%-12.3 \%-6.7 \%$ of the total variability among samples for negative, positive and APGC datasets respectively. High and low tide samples were clustered and distinguished mainly along the first axis for negative and positive ionization condition and along the second axis for APGC. The model fitted the data well. However, too many variables were considered to highlight a specific contribution to the total variability within both datasets.

Hotelling's $\mathrm{T}^{2}$ statistic tested the presence of outliers measuring the variation within the PCA model. Samples with large Hotelling $\mathrm{T}^{2}$ had an unusual variation inside the model. In this case, they were not representative of the modeled data and can be considered as outliers if P-value $<0.05$. The PCA results showed two outlier samples in the negative (4B2 and $3 \mathrm{H} 2$ ) and one outlier in the positive mode (2H3) of datasets. Two strong outlier samples (4B1 and 4H3) were found and removed after a first PCA in APGC dataset. As the two strong outliers completely masked the general PCA model trend, the figure 2 presents a second PCA we performed after exclusion of both strong outlier samples. Two other outlier samples were detected in APGC dataset after this second PCA (6H1 and 1B1). All outlier samples were removed from each sample matrix datasets to perform PLS-DA.

\section{PLS-DA analyses}

PLS-DA analyses were then performed to identify metabolites whose abundance was linked to the tidal cycle. First PLS-DA models were built to force the separation between the two tidal patterns in the three datasets (negative and positive LC-MS and APGC).

The performances of the model was proven, as the results of both analyses for negative, positive modes and APGC datasets showed a relative data consistency with $\mathrm{R}^{2}$ (cumulative) $=0.99,0.99$ and 0.99 respectively. Moreover, the prediction performance of the models reached $\mathrm{Q}^{2}$ (cumulative) $=$ $0.86,0.84$ and 0.81 for negative and positive modes and APGC datasets respectively, estimating a good predictive capacity. 
To improve the prediction performance of the model and to select the variables presenting the most important contribution in the classification model, successive PLS-DA models were built selecting each time only variables with VIP $>1$. Model succession was stopped when their predictive performances were the highest. In the negative mode dataset, a total of two successive models selecting 527 and 204 metabolites with VIP > 1 were performed reaching $\mathrm{Q}^{2}=0.94$. In the positive mode dataset, one supplementary model selecting 85 metabolites with VIP > 1 was performed reaching $\mathrm{Q}^{2}=0.89$. Finally in the APGC dataset, one supplementary model selecting 215 metabolites with VIP > 1 were performed reaching $\mathrm{Q}^{2}=0.83$.

All these selected metabolites showed a clear tidal rhythmic pattern, with a significant difference between low tide and high tide samples for each metabolite (t-test, P-value < 0.05). Among them, 15 metabolites were identified by using one of the identification methods described in the "Material and Methods" section. Interestingly, the relative abundance of 14 metabolites peaked in low tide samples while only tyrosine peaked in high tide samples.

\section{Carbohydratelenergy metabolism}

Within the gill tissue of $M$. varia, all confirmed metabolites presented the same trends: a positive modulation at the end of the $2 \mathrm{~h}$ of emergence and a negative modulation at the end of the $10 \mathrm{~h}$ of immersion.

Concerning metabolites involved in Krebs cycle, succinate was found to be the most oscillating metabolite and malate to a lesser extent. Both compounds exhibited a strong rhythmic fluctuation, with high levels at the end of the two hours emersion period and lower levels at the end of the ten hours immersion periods (Figure 3A). For succinate a difference of about five in relative abundance was found between end of emersion and immersion (P-value $<0.0001)$. Levels of malate, which is an intermediate metabolite formed during the reduction of oxaloacetate to succinate, also increased at low tide (P-value $=0.0016$ ), with a difference of 2.64. Citrate presented the same oscillation pattern, with a difference of two in relative abundance $(\mathrm{P}$-value $=0.01)($ Figure $3 \mathrm{~A})$.

Propionate, which is produced by a further reduction of succinate, could not be detected in any of the samples.

A first type of anaerobic pathway in bivalves is the production of lactate from pyruvate. It appears in the present case, that the abundance of lactate was cyclical with high levels of lactate at the end of low tide and low levels at the end of high tide, with a difference of about three between low and high tides (P-value < 0.0001) (Figure 3B).

Another anaerobic pathway is the reduction of aspartate, resulting in the formation of succinate and alanine via glutamate. In the present study, the abundance of glutamate and alanine was also found to clearly oscillate with high levels at the end of low tide and low level at the end of high tide (amplitude respectively equal to 8.4 and 1.3 and P-values respectively less than 0.0001 and 0.015 ) (Figure 3B). 


\section{Carnitine-conjugated metabolites}

Another striking fact is the increase of carnitine-conjugated metabolites at the end of the two hours emersion periods, with a clear oscillating pattern of relative abundance, with high level at low tides and low level at high tides. A carnitine derivative of a short fatty acid, propionylcarnitine, was first identified as an oscillating metabolite (Figure 4A). Four other derivatives of long fatty acids, stearoylcarnitine, palmitoylcarnitine, hexadecenoylcarnitine and elaidoylcarnitine were also identified and followed the same trend (Figure 4B). Finally, isovalerylcarnitine and isobutyrylcarnitine were also identified as metabolites with a rhythmic pattern linked to tide cycles (Figure 4A).

\section{Other metabolites}

Another metabolite whose abundance peaked during low tide was urate. The level of this metabolite, which is an intermediate metabolite formed during the degradation of purines in presence of the enzyme xanthine oxidase, increased at low tide (P-value $<0.0001)$, with a difference of about 3.5 (Figure 5).

Conversely, tyrosine was more abundant at high tide compared to low tide, with a ratio of relative abundance low/high equal to 0.74 with a P-value $<0.0001$ (Figure 5).

\section{Antioxidant enzyme activities}

The comparison of SOD specific activities measured in the gills of Mimachlamys varia between low and high tide can be made for both tidal cycle during the three days of experiment and is presented in the Figure 6. Regarding the three days, each tidal cycle presents a similar pattern between the low and the high tides. Indeed, specific activities of SOD level increases significantly (approximatively 25\%) at high tide compared to low tide, even if there is a contrary result for the first tidal cycle of day 1 . It was interesting to compare the first low tide of this study which has a regular signal $(32.43 \pm 0.89$ $\mathrm{UI} / \mathrm{mg}$ of proteins) in comparison with the second (33.29 $\pm 0.33 \mathrm{UI} / \mathrm{mg}$ of proteins) and the third day (35.17 $\pm 0.86 \mathrm{UI} / \mathrm{mg}$ of proteins). Moreover, a down modulation in variegated scallop gills was observed at the first high tide (first day) which showed average values of $27.80 \pm 1.3 \mathrm{UI} / \mathrm{mg}$ of proteins. Finally, a high modulation was noted at the second high tide of the first day $(39.49 \pm 1.9$ $\mathrm{UI} / \mathrm{mg}$ of proteins) then the SOD specific activity remained relatively constant afterwards during experimentation.

\section{Discussion}

The gills in bivalves are the first interface between external and internal environments and thus, firstly exposed to changes in oxygen concentrations during the different phases of immersion and emersion. In the present study gill samples collected in scallops at the end of six consecutive immersion and 
emersion periods, simulating a tidal regime, presented significant oscillating variations in the levels of different metabolites. These variations reflected a switch from aerobic to anaerobic energy metabolism at low tide, an accumulation of many different carnitine-conjugated components and the appearance or disappearance of some other metabolites at low tide. The specific activity of SOD presented also an oscillating pattern between low and high tide. These different effects are successively discussed below.

\section{Carbohydrate/energy metabolism}

At low tide, the increase in succinate and malate to a lesser extent on the one hand and of lactate, glutamate and alanine on the other hand suggests that scallops resort to anaerobic energy production after a two hours' time period of emersion. This strategy has been identified since the 1970s in bivalves that undergo periods of hypoxia (De Zwaan and Van Marrewijk, 1973; De Zwaan and Zandee, 1972; Kluytmans et al., 1977). The most used anaerobic pathways for marine bivalves over an emersion period of hours are (1) glucose-lactate pathway with lactate as end-product, (2) glucoseopines pathways, with opines, such as alanopine, strombine and octopine, as end-products, (3) glucose-succinate pathway, with succinate as end-product and (4) aspartate-succinate pathway with succinate and alanine as end products (Hochachka, Peter W. and Somero, G. N., 1984).

The present study indicates that emerged scallops use alternative methods (1), (3) and (4) that do not require oxygen for producing ATP. Indeed, lactate accumulates after 2 hours of emersion, coming from the reduction of pyruvate by the enzyme lactate dehydrogenase with simultaneous oxidation of NADH (pathway 1); succinate and malate, respectively 5 and 2 times more abundant after 2 hours of emersion, are produced via the part of the Krebs cycle between oxaloacetate and succinate running in reverse (Muller et al., 2012). The transformation of oxaloacetate into malate is possible as the enzyme malate dehydrogenase that would oxidize malate into oxaloacetate during "normal" Krebs cycle, catalyze the inverse reaction in anoxic conditions (De Zwaan, 1983) (pathway 3). Finally, the pyruvate is transformed into alanine using an amino group donated via transaminase reactions from aspartate; the resulting oxaloacetate is further metabolized into succinate. This leads to an increase of both alanine and succinate at the end of the emersion period (pathway 4).

Energy is produced faster in pathways (1) but in a less efficient way (two moles of ATP per glucose unit) than pathways (3) and (4), which can yield two times more ATP. Pathway (2) with opines as end products has been identified in scallops in case of temporary muscle anoxia, associated for example with high energy production following burst activity, such an escape swimming (Muller et al., 2012). This pathway has not been observed in case of long term anaerobiosis (Shumway and Parsons, 2016) and opines were not identified in the present study as oscillating metabolites between low and high tides.

In a previous study concerning the survey of genetic variations among four scallop species including Mimanchlamys varia, LDH locus was not detected in M. varia, whereas it was detected at a very low 
level in Pecten maximus (Beajmont and Beveridge, 1984). This finding may be inconsistent with our results showing the accumulation of lactate after two hours of emersion. Nevertheless, those results are relatively old and obtained thanks to electrophoresis, a much less sensitive technique than mass spectrometry. Furthermore in another study of the same period (Livingstone et al., 1983), LDH was identified in the adductor muscle of a closely-related Pectinidae species, Chlamys opercularis, after specific enzyme activity measurement using spectrophotometric method.

Citrate is another metabolite that was found to accumulate at low tide in the present study. This may be because a minor proportion of malate is following the tricarboxylic acid cycle in the forward direction, while the major portion of malate is metabolized via the reverse of that portion of the Krebs cycle : malate-fumarate-succinate (De Zwaan et al., 1981).

Finally, glutamate was also found to accumulate at the end of the emersion period. This metabolite is used with aspartate to maintain the glycolytic flux, through the transformation of pyruvate to alanine by transamination reactions of these free amino acids. In this process, glutamate is transformed into alanine by the action of glutamate pyruvate transaminase and regenerated from ketoglutarate in the glutamate dehydrogenase reaction (Grieshaber et al., 1994). As the relative abundance of alanine was shown to increase at low tide, it is very likely that this metabolic cycle occurs in Mimachlamys varia. This pathway is a characteristic feature of many anoxia-tolerant marine invertebrates (Muller et al., 2012). Nevertheless, it cannot explain the observed accumulation of glutamate at low tide, as this process involves simultaneous formation and consumption of glutamate.

Furthermore, glutamate plays a key role in the catabolism of amino acids, during removal of $\alpha$-amino nitrogen from almost all of the amino acids via transdeamination: amino groups from most amino acids are transferred to $\alpha$-ketoglutarate to form glutamate and an $\alpha$-keto-acid. Glutamate is then transported into the mitochondria, where the amino group may be removed to form ammonia. This last compound is the major nitrogenous excretory product in bivalves, unlike in vertebrates where excess ammonia is excreted as urea or uric acid. Ammonia excreted by bivalves while immersed diffuses into the surrounding water, but bivalves in general exhibit a reduction in rate of ammonia excretion during air exposure and ammonia accumulates in the hemolymph and in the fluid trapped in the mantel cavity (De Vooys and De Zwaan, 1978; Mingoa-licuanan, 1993; Sadok et al., 1999; Thomsen et al., 2016). The increase in glutamate concentration instead of ammonia could then be a way to avoid an excessive accumulation of ammonia, which can strongly affect the animal. However this explanation remains hypothetical and requires confirmation in further studies.

Propionate is a frequently observed metabolite during anaerobiosis in bivalves, in particular under conditions of prolonged anaerobiosis (Muller et al., 2012). In the present study, the absence of 
propionate at the end of the 2 hours' time period of emersion is consistent with studies performed with other bivalves, showing that propionate production is initiated only after longer periods of anoxia. In Mytilus edulis, during the early phase of hypoxia, succinate is produced via the part of the Krebs cycle between oxaloacetate and succinate running in reverse and under conditions of prolonged anaerobiosis, propionate is preferentially formed instead of succinate (Muller et al., 2012). The same delay between succinate and propionate production during hypoxia was observed in Mytillus galloprovincialis. After exposure of this mussel to anaerobiosis in laboratory, propionate was not detected after $6 \mathrm{~h}$ in anoxic seawater, whereas a sevenfold increase in succinate was observed, but accumulated after $24 \mathrm{~h}$ of incubation. After $48 \mathrm{~h}$, propionate concentrations increased by a factor of two with regard to $24 \mathrm{~h}$ for individuals incubated in anoxic seawater and appeared, for the first time, in emersed individuals (Babarro et al., 2007).

In summary, our results show a clear signal of increased anaerobic capacity after only $2 \mathrm{~h}$ of aerial exposure. Low oxygen concentrations during emersion will decrease the oxidative phosphorylation of ATP, which will induce the activation of alternative metabolic pathways of ATP production. This strategy does not discard other ones like, for example, lowering metabolism and the recourse to gaseous air breathing, but it means that scallops cannot meet their total energy requirements without using anaerobic metabolism.

\section{Carnitine-conjugated metabolites}

As shown in the results section, many carnitine-conjugated metabolites were shown to accumulate at the end of the 2 hours emersion periods. This accumulation is related to a decline in mitochondrial metabolism in hypoxia, in particular fatty acid catabolism, that seems to be paused at low tide. Indeed, in normoxic conditions, the oxidation of fatty acids is an important source of energy for ATP production in mitochondria through the supply of acetyl-Coenzyme A (CoA) to the Krebs cycle. Fatty acids are first activated in the cytosol by esterification with CoA to give acyl-CoA. Long chain acylCoA cannot penetrate the mitochondrial inner membrane and have to be conjugated to carnitine, which acts as a carrier. In the present case, stearoyl-,palmitoyl-, hexadecenoyl- and elaidoyl-CoA, which accumulate after 2 hours of emersion, remain blocked in this form, instead of being further oxidized into acety-CoA. Similarly,propionylcarnitine increases at low tide. This compound is a product of oddchain fatty acid catabolism; it can be metabolized to succinyl-CoA, which can then enter the Krebs cycle in normoxic conditions. In the present study, it appears that propionylcarnitine accumulates in hypoxia. Finally, isovalerylcarnitine, isobutyrylcarntine are also found to increase at low tide. These compounds are intermediates of leucine and valine catabolism respectively, which can also serve as an energy source, in providing acetyl-CoA or propionyl-CoA after catabolism. The accumulation of carnitine conjugates during low tides has already been observed in the case of Mytilus californianus (Connor and Gracey, 2012; Gracey and Connor, 2016). This was considered as a way to regulate 
different metabolic pathways for the organism. In particular, it prevents acyl-CoA accumulation in the cytoplasm ad mitochondria that could lead to serious disorder.

It was reported that the ratio of acetyl-CoA to CoA has important effects on overall mitochondrial metabolism and therefore the accumulation of carnitine-conjugated metabolites at low tides would be a way to regulate this ratio (Connor and Gracey, 2012). In summary, this accumulation of many different carnitine-conjugated compounds after 2 hours of emersion is a response to tissue hypoxia, with a switch from oxidative phosphorylation to anaerobic metabolism. As outlined by Gracey and Connor in previous study concerning Mytilus edulis, this mechanism of accumulation of carnitineconjugated compounds at low tide, is also a way to store potential energy that can be quickly converted to ATP when animals return to oxygen-rich submerged conditions (Gracey and Connor, 2016).

\section{Other metabolites}

Finally, two supplementary metabolites were found to oscillate with tidal cycles: urate was higher at the end of the 2 hours emersion period and tyrosine higher at the end of the immersion period.

Concerning the accumulation of urate during emersion, this metabolite was shown to accumulate in crustaceans, scallops and cockles during hypoxia and would arise from adenylate degradation in presence of the enzyme xanthine oxidase (XOD) (Dykens and Shick, 1988). In the catabolism of purine nucleotides, AMP is degraded to inosine and then by phosphorolysis to hypoxanthine. In presence of XOD, xanthine is formed from oxidation of hypoxanthine. Xanthine is again oxidized by XOD to form the final product: urate and superoxide radicals $\left(\mathrm{O}_{2}^{-}\right)$in presence of oxygen. XOD activity has been assayed in different bivalves after periods of anoxia. It was not detected in members of the orders Mytiloida and Myoida, but it was found in scallops (Pecten maximus and Placopecten magellanicus) (Dykens and Shick, 1988). So it appears that anoxia-tolerant bivalves, like Mytilus edulis, avoid accumulating hypoxanthine, because they present low activity of XOD. Conversely anoxia-sensitive (or more intolerant to anoxic-normoxic transitions) bivalves, like Pecten maximus, undergo hypoxanthine accumulation and are subjected to superoxide radicals when oxygen is available again, as they present XOD activity.

So, as urate accumulates during emersion in gills of Mimachlamys varia, this species likely displays XOD activity during emersion, as urate is the end product of this enzyme. According to the study of Dykens, this is linked to a low tolerance to anoxic environment or to anoxic-normoxic transitions. This is consistent with the fact that pectinidae are not well-adapted to emersion, compared to mytilidae. They are adapted to brief functional hypoxia, for example during swimming, but do not survive prolonged environmental hypoxia (Riedel 2012).

As far as the accumulation of tyrosine after 2 hours of emersion is concerned, this may be linked to the role of this amino acid in the formation of catecholamines, neurotransmitters that are present in both central nervous system and hemolymph of bivalves. The enzyme tyrosine hydroxylase enables the 
conversion of tyrosine to the precursor of catecholamines L-dihydroxyphenylalanine (L-DOPA). It was shown that under the effect of unfavorable environmental factors, the quantitative catecholamine contents vary (Kotsyuba, 2011). Moreover these substances exert marked cilio-excitatory or cilioinhibitory actions when applied to the bivalve gill (Malanga et al., 1972). Lateral cilia of bivalve gills serve a vital function by generating the water currents that allow gas exchange as well as regulate food intake and waste removal. Numerous studies indicate that the beating of the lateral cilia of bivalve gills is under nervous or neurohormonal control in various bivalves. For example, lateral cilia of the gill of Mytilus edulis are controlled by a reciprocal serotonergic-dopaminergic innervation from their ganglia (Carroll and Catapane, 2007). Taking these facts into account, the accumulation of tyrosine may be linked to this regulation system, in order to enhance the beating of cilia in case of hypoxia, through a reduced transformation of tyrosine to dopamine, that would have indirectly a cilio-inhibitory effect (Carroll and Catapane, 2007). This hypothesis is however only one assumption at this stage of the study.

\section{SOD activity}

In the present study, SOD activity measurements showed lower levels of antioxidant enzyme specific activity during low tides, after two hours of emersion, compared to the high tides. The alternation of immersion-submersion for intertidal organisms implies fluctuations in temperature, radiation exposure and oxygen supply as well, which have an impact on free radical and reactive oxygen species (ROS) production. For example, the elevation of $\mathrm{O}_{2}$ respiration in reoxygenation during re-immersion has been suggested to result in the enhanced ROS production in intertidal organisms (Yin et al., 2017). To protect themselves against ROS, intertidal organisms have developed a system with enzymatic antioxidants, including superoxide dismutase (SOD), catalase (CAT), glutathione peroxidase (GPx), and ascorbate peroxidase (APX). The oxidative stress occurring when higher level of oxygen is introduced during re-immersion is intense for these organisms. Thus, it is therefore suggested that the higher level in SOD activity in gills of scallops observed in the present study could be a response of acclimation to a higher level of encountered oxidative stress upon re-immersion. In previous studies, opposite results were obtained : increased activities of SOD and CAT were shown in clams under air exposure compared to clams without air exposure (Yin et al., 2017) and an increase in antioxidant defenses was shown to be induced by short-term hypoxia in marine invertebrates including bivalves (Nogueira et al., 2017). So it appears that hypoxia associated with air exposure, is not systematically accompanied by low SOD activity level compared to normoxia obtained upon re-immersion. Nevertheless, in any case, alternating periods of immersion and aerial emergence seems to be accompanied by variations of SOD activity in intertidal inhabitants. 


\section{Conclusion}

The purpose of this study was to investigate the metabolic strategy of Mimachlamys varia under alternating short period of emersion and longer period of immersion, mimicking conditions that might be experienced by scallops, located highest on the shore, during extreme spring and autumn tides. Our results show that there is a switch from aerobic to anaerobic metabolism after only two hours of emersion, with the resort to different pathways used by other bivalves to face hypoxia: glucose-lactate pathway with lactate as end-product, glucose-succinate pathway, with succinate as end-product and aspartate-succinate pathway. Furthermore, carnitine-conjugated metabolites were found to accumulate after two hours of emersion, as well as urate. The level of tyrosine on the contrary was found to increase upon emersion. Moreover, SOD activity was found to increase upon re-immersion. These different findings concerning oscillating metabolites and enzymatic response indicate a complex metabolic reprogramming that occurs after an emersion period of two hours only and upon reimmersion. To our knowledge, it is the first time that this physiological adaptation to emersion is studied in Mimachlamys varia. It appears that, like many bivalve organisms undergoing hypoxianormoxia transitions, variegated scallops have developed a high metabolic flexibility and may have evolved tissue-specific abilities to deal with the abrupt exposure of gills to molecular oxygen upon reimmersion. In accordance with previous studies in mussels in the same organ (Letendre et al., 2008), the gills of the variegated scallop seem to be an adapted organ to assess hypoxia response after a short emersion (two hours) for future experiments.

Further studies will be required to completely elucidate this metabolic and physiologic reorganization. In particular, absolute quantification of metabolite levels and flux measurements are needed, and also the evaluation of a possible global lowering metabolism upon emersion and the measure of the exact recourse to gaseous air breathing.

These findings have to be taken into account to homogenize sampling during campaigns of environmental monitoring, by taking in situ, as far as possible only individuals in immersion. The biomarker response depends on the moment of the tidal cycle as well as on the ambient environment in which are living the bivalves. This could be related to different abiotic factors such as oxygenation and temperature conditions, which change at the upper side of the shore compared to the lower part. It results in different impacts on the metabolism and per consequence on the physiology of the variegated scallop.

\section{Acknowledgements}

We acknowledge I. Goubet (from laboratory "Littoral Environnement et Sociétés" (LIENSs), UMR 7266, CNRS-Université de La Rochelle, 2 rue Olympe de Gouges, F-17042 La Rochelle Cedex 01, France) and A. Y. Gracey (from Marine Environmental Biology, Univ. of Southern California, 3616 Trousdale Pkwy, Los Angeles, CA 90089, United States) for fruitful discussions and exchanges. The 
authors thank Y. Guitton (from LABERCA - ONIRIS, Route de Gachet - CS 50707 - 44307 Nantes

Cedex 3, France) for APGC-ToF MS analysis and fruitful discussions.

\section{Funding sources}

Funding for this work came from the following separate sources: (i) the INCREASE CNRS Federation

(FR CNRS 3707), (ii) a research grant from the "Communauté d'Agglomération of La Rochelle" and

(iii) Contrat de Plan Etat-Région FEDER and the CNRS ECONAT Axe 1 - Ressources Marines Littorales: qualité et éco-valorisation.

\section{REFERENCES}

Akberali, H.B., Trueman, E.R., 1985. Effects of Environmental Stress on Marine Bivalve Molluscs, in: Advances in Marine Biology. Elsevier, pp. 101-198. https://doi.org/10.1016/S00652881(08)60051-6

Babarro, J.M.F., Labarta, U., Reiriz, M.J.F., 2007. Energy metabolism and performance of Mytilus galloprovincialis under anaerobiosis. J. Mar. Biol. Assoc. UK 87, 941. https://doi.org/10.1017/S0025315407053726

Beajmont, A.R., Beveridge, C.M., 1984. Electrophoretic survey of genetic variation in Pecten maximus, Chlamys opercularis, C. varia and C. distorta from the Irish Sea. Mar. Biol. 81, 299-306. https://doi.org/10.1007/BF00393224

Breitwieser, M., Vigneau, E., Viricel, A., Becquet, V., Lacroix, C., Erb, M., Huet, V., Churlaud, C., Le Floch, S., Guillot, B., Graber, M., Thomas, H., 2018. What is the relationship between the bioaccumulation of chemical contaminants in the variegated scallop Mimachlamys varia and its health status? A study carried out on the French Atlantic coast using the Path ComDim model. Sci. Total Environ. 640-641, 662-670. https://doi.org/10.1016/j.scitotenv.2018.05.317

Breitwieser, M., Viricel, A., Graber, M., Murillo, L., Becquet, V., Churlaud, C., Fruitier-Arnaudin, I., Huet, V., Lacroix, C., Pante, E., Le Floch, S., Thomas-Guyon, H., 2016. Short-Term and Long-Term Biological Effects of Chronic Chemical Contamination on Natural Populations of a Marine Bivalve. PLOS ONE 11, e0150184. https://doi.org/10.1371/journal.pone.0150184

Carroll, M.A., Catapane, E.J., 2007. The nervous system control of lateral ciliary activity of the gill of the bivalve mollusc, Crassostrea virginica. Comp. Biochem. Physiol. A. Mol. Integr. Physiol. 148, 445-450. https://doi.org/10.1016/j.cbpa.2007.06.003

Connor, K.M., Gracey, A.Y., 2012. High-resolution analysis of metabolic cycles in intertidal mussel Mytilus californianus. Am. J. Physiol.-Regul. Integr. Comp. Physiol. 302, 103-111.

De Vooys, C.G.., De Zwaan, A., 1978. The rate of oxygen consumption and ammonia excretion by Mytilus edulis after various periods of exposure to air. Comp. Biochem. Physiol. A Physiol. 60, 343-347. https://doi.org/10.1016/0300-9629(78)90259-1

De Zwaan, A., 1983. Carbohydrate Catabolism in Bivalves, in: The Mollusca, Vol. 1 Metabolic Biochemistry and Molecular Biomechanics. Hochachka PW, New-York, pp. 13-175. https://doi.org/10.1016/B978-0-12-751401-7.50011-9

De Zwaan, A., Holwerda, D.A., Veenhof, P.R., 1981. Anaerobic malate metabolism in mitochondria of the sea mussel Mytilus edulis L. Mar. Biol. Lett. 2, 131-140.

De Zwaan, A., Van Marrewijk, W.J.A., 1973. Anaerobic glucose degradation in the sea mussel Mytilus edulis L. Comp. Biochem. Physiol. 44B, 429-439.

De Zwaan, A., Wijsman, T.C.M., 1976. Anaerobic metabolism in bivalvia (Mollusca) Characteristics of anaerobic metabolism. Comp. Biochem. Physiol. Part B Comp. Biochem. 54, 313-323. https://doi.org/10.1016/0305-0491(76)90247-9 
De Zwaan, A., Zandee, D.I., 1972. The utilization of glycogen and accumulation of some intermediates during anaerobiosis in Mytilus edulis L. Comp. Biochem. Physiol. Part B Comp. Biochem. 43, 47-54. https://doi.org/10.1016/0305-0491(72)90200-3

Dudognon, T., Soudant, P., Seguineau, C., Quéré, C., Auffret, M., Kraffe, E., 2013. Functional capacities of gill mitochondria in oyster Crassostrea gigas during an emersion/immersion tidal cycle. Aquat. Living Resour. 26, 249-256. https://doi.org/10.1051/alr/2013053

Duncan, P.F., Brand, A.R., Strand, Ø., Foucher, E., 2016. The European Scallop Fisheries for Pecten maximus, Aequipecten opercularis, Chlamys islandica, and Mimachlamys varia, in: Developments in Aquaculture and Fisheries Science. Elsevier, pp. 781-858. https://doi.org/10.1016/B978-0-444-62710-0.00019-5

Dykens, J.A., Shick, J.M., 1988. Relevance of purine catabolism to hypoxia and recovery in euryoxic and stenoxic marine invertebrates, particularly bivalve molluscs. Comp. Biochem. Physiol. Part C Comp. Pharmacol. 91, 35-41. https://doi.org/10.1016/0742-8413(88)90166-1

Gracey, A.Y., Connor, K., 2016. Transcriptional and metabolomic characterization of spontaneous metabolic cycles in Mytilus californianus under subtidal conditions. Mar. Genomics 30, 35 41. https://doi.org/10.1016/j.margen.2016.07.004

Grieshaber, M.K., Hardewig, I., Kreutzer, U., Pörtner, H.O., 1994. Physiological and metabolic responses to hypoxia in invertebrates. Rev. Physiol. Biochem. Pharmacol. 125, 43-147.

Hochachka, Peter W., Somero, G. N., 1984. Limiting oxygen availability, in: Biochemical Adaptation. W. Hochachka and G.N. Somero, Princeton, New Jersey, pp. 145-181.

Isani, G., Cattani, O., Zurzolo, M., Pagnucco, C., Cortesi, P., 1995. Energy metabolism of the mussel, Mytilus galloprovincialis, during long-term anoxia. Comp. Biochem. Physiol. B Biochem. Mol. Biol. 110, 103-113. https://doi.org/10.1016/0305-0491(94)00132-E

Jaeger, C., Hoffmann, F., Schmitt, C.A., Lisec, J., 2016. Automated Annotation and Evaluation of InSource Mass Spectra in GC/Atmospheric Pressure Chemical Ionization-MS-Based Metabolomics. Anal. Chem. 88, 9386-9390. https://doi.org/10.1021/acs.analchem.6b02743

Kluytmans, J.H., de Bont, A.M.T., Janus, J., Wusman, T.C.M., 1977. Time dependent changes and tissue specificities in the accumulation of anaerobic fermentation products in the sea mussel Mytilus edulis L. Comp. Biochem. Physiol. Part B Comp. Biochem. 58, 81-87. https://doi.org/10.1016/0305-0491(77)90131-6

Kotsyuba, E.P., 2011. Distribution and ultrastructure of tyrosine hydroxylase-positive neurons in CNS of bivalve mollusc Megangulus venulosus under action of elevated temperature and hypoxia. Cell Tissue Biol. 5, 264-272. https://doi.org/10.1134/S1990519X11030047

Letendre, J., Chouquet, B., Rocher, B., Manduzio, H., Leboulenger, F., Durand, F., 2008. Differential pattern of $\mathrm{Cu} / \mathrm{Zn}$ superoxide dismutase isoforms in relation to tidal spatio-temporal changes in the blue mussel Mytilus edulis. Comp. Biochem. Physiol. Part C Toxicol. Pharmacol. 148, 211-216. https://doi.org/10.1016/j.cbpc.2008.05.012

Livingstone, D.R., de Zwaan, A., Leopold, M., Marteijn, E., 1983. Studies on the phylogenetic distribution of pyruvate oxidoreductases. Biochem. Syst. Ecol. 11, 415-425. https://doi.org/10.1016/0305-1978(83)90047-9

Malanga, C.J., Wenger, G.R., Aiello, E.L., 1972. Endogenous dopamine in bivalve gills. Comp. Biochem. Physiol. 43A, 825-830.

Metian, M., Bustamente, P., Hédouin, L., Oberhänsli, F., Warnau, M., 2009a. Delineation of heavy metal uptake pathways (seawater and food) in the variegated scallop Chlamys varia, using radiotracer techniques. Mar. Ecol. Prog. Ser. 375, 161-171. https://doi.org/10.3354/meps07766

Metian, M., Warnau, M., Oberhänsli, F., Bustamante, P., 2009b. Delineation of Pb contamination pathways in two Pectinidae: The variegated scallop Chlamys varia and the king scallop Pecten maximus. Sci. Total Environ. 407, 3503-3509. https://doi.org/10.1016/j.scitotenv.2009.02.010

Milinkovitch, T., Bustamante, P., Huet, V., Reigner, A., Churlaud, C., Thomas-Guyon, H., 2015. In situ evaluation of oxidative stress and immunological parameters as ecotoxicological biomarkers in a novel sentinel species (Mimachlamys varia). Aquat. Toxicol. 161, 170-175. https://doi.org/10.1016/j.aquatox.2015.02.003 
Mingoa-licuanan, S.S., 1993. Oxygen consumption and ammonia excretion in juvenile Tridacna gigas (Linne, 1758): effects of emersion. J. Exp. Mar. Biol. Ecol. 171, 119-137. https://doi.org/10.1016/0022-0981(93)90144-D

Mondeguer, F., Abadie, E., Herve, F., Bardouil, M., Sechet, V., Raimbault, V., Berteaux, T., Zendong, S.Z., Palvadeau, H., Amzil, Z., Hess, P., Fessard, V., Huguet, A., Sosa, S., Tubaro, A., Aráoz, R., Molgó, J., 2015. Pinnatoxines en lien avec l'espèce Vulcanodinium rugosum (II). http://archimer.ifremer.fr/doc/00285/39635/

Muller, M., Mentel, M., van Hellemond, J.J., Henze, K., Woehle, C., Gould, S.B., Yu, R.-Y., van der Giezen, M., Tielens, A.G.M., Martin, W.F., 2012. Biochemistry and Evolution of Anaerobic Energy Metabolism in Eukaryotes. Microbiol. Mol. Biol. Rev. 76, 444-495. https://doi.org/10.1128/MMBR.05024-11

Nogueira, L., Mello, D.F., Trevisan, R., Garcia, D., da Silva Acosta, D., Dafre, A.L., de Almeida, E.A., 2017. Hypoxia effects on oxidative stress and immunocompetence biomarkers in the mussel Perna perna (Mytilidae, Bivalvia). Mar. Environ. Res. 126, 109-115. https://doi.org/10.1016/j.marenvres.2017.02.009

Paoletti, F., Aldinucci, D., Mocali, A., Caparrini, A., 1986. A sensitive spectrophotometric method for the determination of superoxide dismutase activity in tissue extracts. Anal. Biochem. 154, 536-541.

Sadok, S., Uglow, R.F., Haswell, S.J., 1999. Some aspects of nitrogen metabolism in Mytilus edulis : effects of aerial exposure. Mar. Biol. 135, 297-305. https://doi.org/10.1007/s002270050627

Shick, J.M., Gnaiger, E., Widdows, J., Bayne, B.L., De Zwaan, A., 1986. Activity and metabolism in the mussel Mytilus edulis L. during intertidal hypoxia and aerobic recovery. Physiol. Zool. 59, 627-642.

Shumway, S.E., Parsons, G.J. (Eds.), 2016. Scallops: biology, ecology and aquaculture, Third Edition. ed, Developments in aquaculture and fisheries science. Elsevier, Amsterdam Boston Heidelberg London New York Oxford Paris San Diego San Francisco Singapore Sydney Tokyo.

Smith, P.K., Krohn, R.I., Hermanson, G.T., Mallia, A.K., Gartner, F.H., Provenzano, M.D., Fujimoto, E.K., Goeke, N.M., Olson, B.J., Klenk, D.C., 1985. Measurement of protein using bicinchoninic acid. Anal. Biochem. 150, 76-85. https://doi.org/10.1016/0003-2697(85)904427

Thomsen, J., Himmerkus, N., Holland, N., Sartoris, F.J., Bleich, M., Tresguerres, M., 2016. Ammonia excretion in mytilid mussels is facilitated by ciliary beating. J. Exp. Biol. 219, 2300-2310. https://doi.org/10.1242/jeb.139550

Valavanidis, A., Vlahogianni, T., Dassenakis, M., Scoullos, M., 2006. Molecular biomarkers of oxidative stress in aquatic organisms in relation to toxic environmental pollutants. Ecotoxicol. Environ. Saf. 64, 178-189. https://doi.org/10.1016/j.ecoenv.2005.03.013

Van Der Kloet, F.M., Bobeldijk, I., Verheij, E.R., Jellema, R.H., 2009. Analytical error reduction using single point calibration for accurate and precise metabolomic phenotyping. J. Proteome Res. 8, 5132-5141.

Yin, X., Chen, P., Chen, H., Jin, W., Yan, X., 2017. Physiological performance of the intertidal Manila clam (Ruditapes philippinarum) to long-term daily rhythms of air exposure. Sci. Rep. 7. https://doi.org/10.1038/srep41648 


\section{Conflict of interest}

I argue that there is no conflict of interest 


\section{Figure captions:}

Figure 1: Simulated tidal regime used. Scallops were emerged during low tides, which occurred from 8.30 AM to $10.30 \mathrm{AM}$ and 8.30 PM to $10.30 \mathrm{PM}$. A light-dark cycle was imposed with periods of darkness occurring from 8.00 PM to 8.00 AM. Scallops were sampled at 8:15 AM, 10:15 AM, 8:15 PM and 10:15 PM.

Figure 2: The score plots of PCA and PLS-DA for negative mode (LC-Negative), positive mode (LCPositive) of liquid chromatography and gas chromatography (APGC). Ellipses on PCA score plots represented the confidence limit (95\%) of Hotelling's T2 statistic.

Figure 3: Products of anaerobiosis exhibiting a cyclical abundance profile, with a high level at the end of low tide and low level at the end of high tide, $\mathrm{X}$-axis, time as represented by the tidal cycle; Y-axis, relative metabolite abundance, A: succinate, malate and citrate, B: lactate, alanine and glutamate.

Figure 4: Carnitine-conjugated exhibiting a cyclical abundance profile, with a high level at the end of low tide and low level at the end of high tide, $\mathrm{X}$-axis, time as represented by the tidal cycle; $\mathrm{Y}$-axis, relative metabolite abundance, A: Isobutyrilcarnitine, Isovalerylcarnitine and Propionylcarnitine B: Palmitoylcarnitine, Hexadecenoylcarnitine, Elaidoylcarnitine and Stearoylcarnitine

Figure 5: Urate and Tyrosine cycling according to the tidal cycle. Urate showed high level at the end of low tide and low level at the end of high tide and Tyrosine followed the opposed trend, X-axis, time as represented by the tidal cycle; Y-axis, relative metabolite abundance.

Figure 6: Antioxidant enzyme (SOD) specific activities with a low level at the end of low tide and high level at the end of high tide. $\mathrm{X}$-axis, time as represented by the tidal cycles during the 3 days of experimentation; $\mathrm{Y}$-axis, SOD specific activity. Results are expressed as means \pm standard error $(\mathrm{n}=$ 9,3 individuals pooled per tide variation, $\mathrm{n}=3$ replicate measurements for each pool). No star is shown above bars when there was no significant statistical difference among cycles at each day (Pvalue $>0,05)$. 
Table 1 Metabolites that oscillate during the tidal cycle

\begin{tabular}{|c|c|c|c|c|c|c|c|c|}
\hline Metabolite & $\begin{array}{l}\text { Platefor } \\
\text { m }\end{array}$ & $\begin{array}{l}\text { Retentio } \\
\text { n time } \\
\text { (s) }\end{array}$ & $\begin{array}{l}\text { Observed } \\
\text { mass } \\
(m / z)\end{array}$ & $\begin{array}{c}\text { Theorical } \\
\text { mass } \\
(m / z)\end{array}$ & $\begin{array}{l}\text { Formula of ion } \\
\text { observed }\end{array}$ & $\begin{array}{c}\text { Mass } \\
\text { error } \\
\text { (ppm } \\
\text { ) }\end{array}$ & $\begin{array}{l}\text { Amplitud } \\
\text { e low- } \\
\text { high tide } \\
\text { ratio }\end{array}$ & P-value \\
\hline Lactate & $\begin{array}{c}\text { LC/MS } \\
\text { Neg }\end{array}$ & 131 & 89.0230 & 89.0239 & $\mathrm{C}_{3} \mathrm{H}_{5} \mathrm{O}_{3}{ }^{1}$ & 10.0 & 3.79 & $\begin{array}{c}<0.000 \\
1\end{array}$ \\
\hline Succinate & $\begin{array}{c}\text { LC/MS } \\
\text { Neg }\end{array}$ & 287 & $\begin{array}{c}117.018 \\
1 \\
\end{array}$ & $\begin{array}{c}117.018 \\
8 \\
\end{array}$ & $\mathrm{C}_{4} \mathrm{H}_{5} \mathrm{O}_{4}{ }^{1}$ & 6.0 & 4.99 & $\begin{array}{c}<0.000 \\
1 \\
\end{array}$ \\
\hline Tyrosine & $\begin{array}{c}\text { LC/MS } \\
\text { Neg }\end{array}$ & 281 & $\begin{array}{c}180.066 \\
0\end{array}$ & $\begin{array}{c}180.066 \\
1\end{array}$ & $\mathrm{C}_{9} \mathrm{H}_{10} \mathrm{NO}_{3}{ }^{1}$ & 0.5 & 0.74 & $\begin{array}{c}<0.000 \\
1\end{array}$ \\
\hline Isobutyrylcarnitine & $\begin{array}{c}\text { LC/MS } \\
\text { Pos }\end{array}$ & 419 & $\begin{array}{c}232.155 \\
4\end{array}$ & $\begin{array}{c}232.154 \\
9\end{array}$ & $\mathrm{C}_{11} \mathrm{H}_{22} \mathrm{NO}_{4}^{2}$ & 2.1 & 8.25 & $\begin{array}{c}<0.000 \\
1\end{array}$ \\
\hline Isovalerylcarnitine & $\begin{array}{c}\text { LC/MS } \\
\text { Pos }\end{array}$ & 454 & $\begin{array}{c}246.171 \\
0 \\
\end{array}$ & $\begin{array}{c}246.170 \\
5 \\
\end{array}$ & $\mathrm{C}_{12} \mathrm{H}_{24} \mathrm{NO}_{4}^{2}$ & 2.0 & 9.80 & $\begin{array}{c}<0.000 \\
1\end{array}$ \\
\hline Propionylcarnitine & $\begin{array}{l}\text { LC/MS } \\
\text { Pos }\end{array}$ & 368 & $\begin{array}{c}218.139 \\
9\end{array}$ & $\begin{array}{c}218.139 \\
2\end{array}$ & $\mathrm{C}_{10} \mathrm{H}_{20} \mathrm{NO}_{4}^{2}$ & 3.2 & 2.15 & 0.0006 \\
\hline $\begin{array}{l}\text { Hexadecenoylcarniti } \\
\text { ne }\end{array}$ & $\begin{array}{c}\text { LC/MS } \\
\text { Pos }\end{array}$ & 992 & $\begin{array}{c}398.326 \\
4\end{array}$ & $\begin{array}{c}398.327 \\
0\end{array}$ & $\mathrm{C}_{23} \mathrm{H}_{44} \mathrm{NO}_{4}{ }^{2}$ & 1.5 & 4.10 & 0.0004 \\
\hline Palmitoylcarnitine & $\begin{array}{c}\text { LC/MS } \\
\text { Pos }\end{array}$ & 1077 & $\begin{array}{c}400.342 \\
1\end{array}$ & $\begin{array}{c}400.342 \\
7\end{array}$ & $\mathrm{C}_{23} \mathrm{H}_{46} \mathrm{NO}_{4}{ }^{2}$ & 1.5 & 2.99 & $\begin{array}{c}<0.000 \\
1\end{array}$ \\
\hline Elaidoylcarnitine & $\begin{array}{c}\text { LC/MS } \\
\text { Pos }\end{array}$ & 1097 & $\begin{array}{c}426.357 \\
5 \\
\end{array}$ & $\begin{array}{c}426.358 \\
3 \\
\end{array}$ & $\mathrm{C}_{25} \mathrm{H}_{48} \mathrm{NO}_{4}{ }^{2}$ & 1.9 & 3.47 & $\begin{array}{c}<0.000 \\
1\end{array}$ \\
\hline Stearoylcarnitine & $\begin{array}{l}\text { LC/MS } \\
\text { Pos }\end{array}$ & 1168 & $\begin{array}{c}428.373 \\
5\end{array}$ & $\begin{array}{c}428.374 \\
0\end{array}$ & $\mathrm{C}_{25} \mathrm{H}_{50} \mathrm{NO}_{4}{ }^{2}$ & 1.2 & 2.70 & 0.001 \\
\hline Glutamate & APGC & 517 & $\begin{array}{c}364.178 \\
4\end{array}$ & $\begin{array}{c}364.179 \\
6\end{array}$ & $\mathrm{C}_{14} \mathrm{H}_{33} \mathrm{NO}_{4} \mathrm{Si}_{3}{ }^{3}$ & 3.3 & 8.37 & $\begin{array}{c}<0.000 \\
1\end{array}$ \\
\hline Urate & APGC & 948 & $\begin{array}{c}456.184 \\
6\end{array}$ & $\begin{array}{c}456.186 \\
4\end{array}$ & $\mathrm{C}_{17} \mathrm{H}_{36} \mathrm{~N}_{3} \mathrm{O}_{3} \mathrm{Si}_{4}$ & 3.9 & 3.52 & $\begin{array}{c}<0.000 \\
1\end{array}$ \\
\hline Citrate & APGC & 736 & $\begin{array}{c}465.163 \\
2\end{array}$ & $\begin{array}{c}465.161 \\
6\end{array}$ & $\mathrm{C}_{17} \mathrm{H}_{37} \mathrm{O}_{7} \mathrm{Si}_{4}{ }^{3}$ & 3.4 & 2.06 & 0.01 \\
\hline Malate & APGC & 385 & $\begin{array}{c}233.102 \\
2\end{array}$ & $\begin{array}{c}233.102 \\
9\end{array}$ & $\mathrm{C}_{9} \mathrm{H}_{21} \mathrm{O}_{3} \mathrm{Si}_{2}{ }^{3}$ & 3.0 & 2.64 & $\begin{array}{c}<0.000 \\
1\end{array}$ \\
\hline Alanine & APGC & & & $\begin{array}{c}144,084 \\
5\end{array}$ & $\begin{array}{c}\mathrm{C} 6 \mathrm{H} 14 \mathrm{~N} 1 \mathrm{O} 1 \mathrm{~S} \\
\mathrm{i}^{3}\end{array}$ & 7,0 & 1,28 & 0,015 \\
\hline
\end{tabular}

${ }^{1}$ Ion formula in negative mode, adducts were $[M-H]$

${ }^{2}$ Ion formula in positive mode, adducts were $[\mathrm{M}+\mathrm{H}]^{+}$

${ }^{3}$ Derivatized with trimethylsilane product formula, adducts were $[\mathrm{M}+\mathrm{H}]^{+}$ 


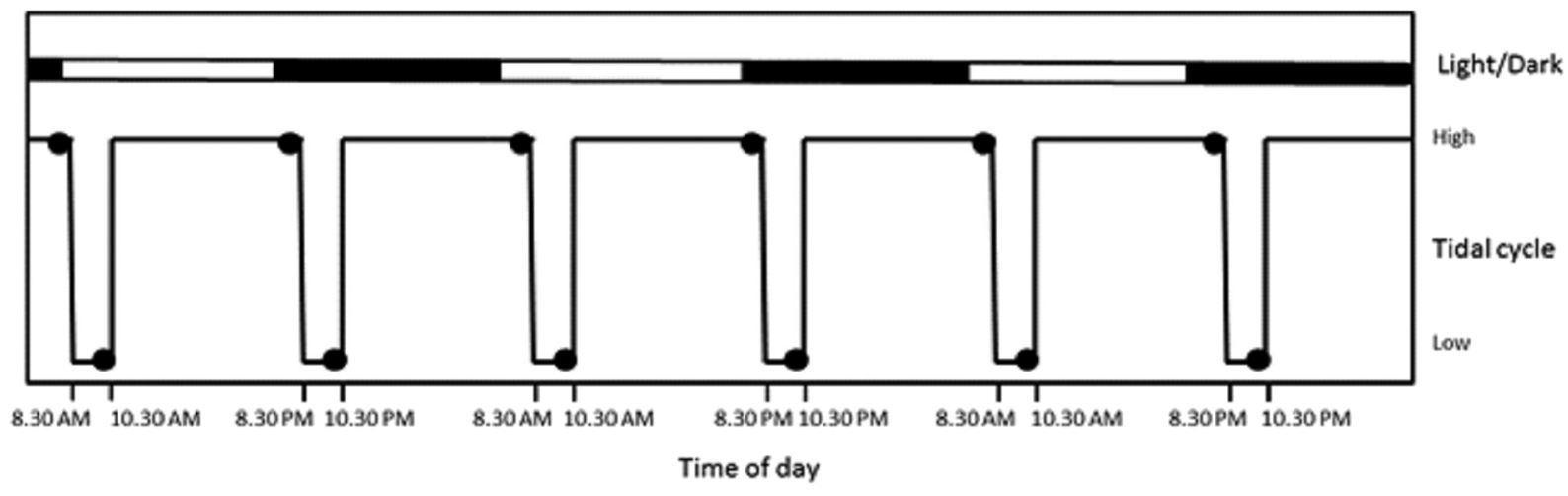

Figure 1 


\section{LC-Negative}
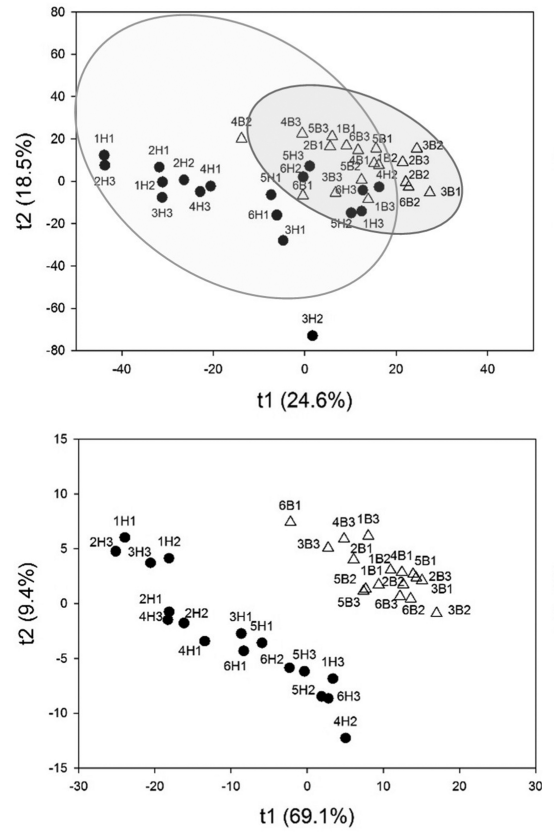

\section{LC-Positive}
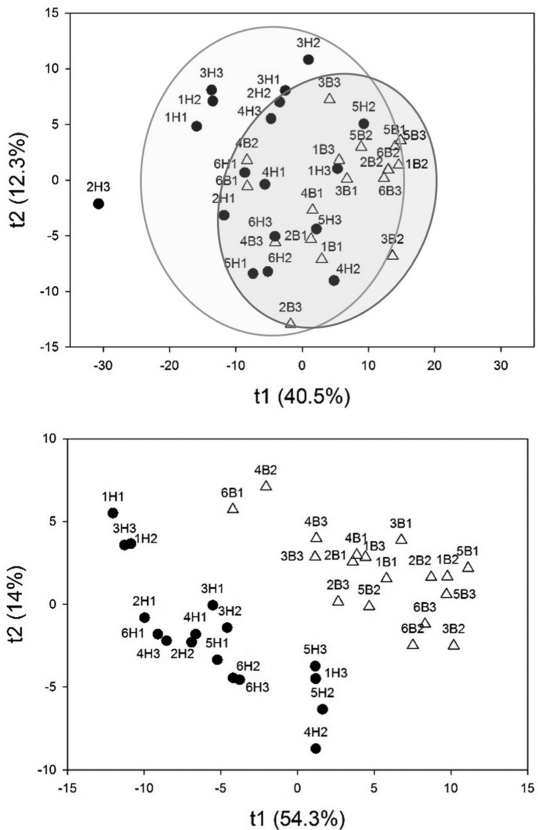

APGC
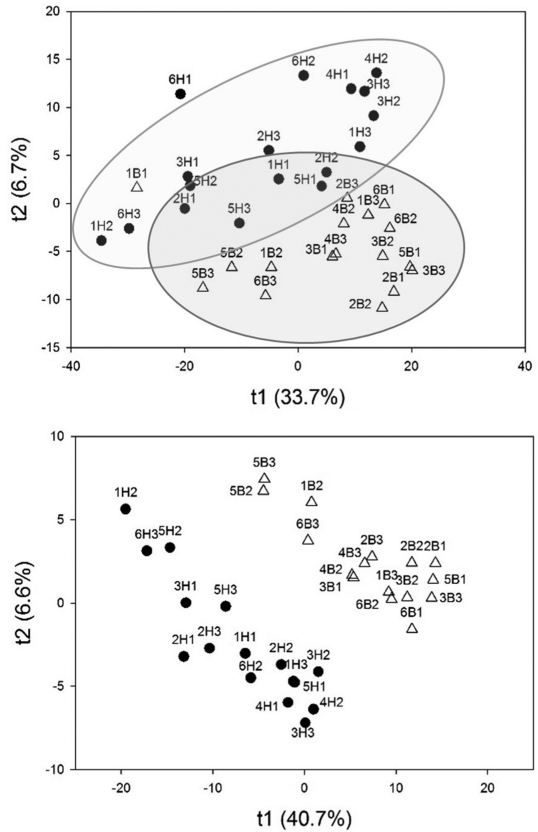

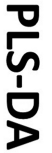

$\triangle \quad$ Low tide samples High tide samples 

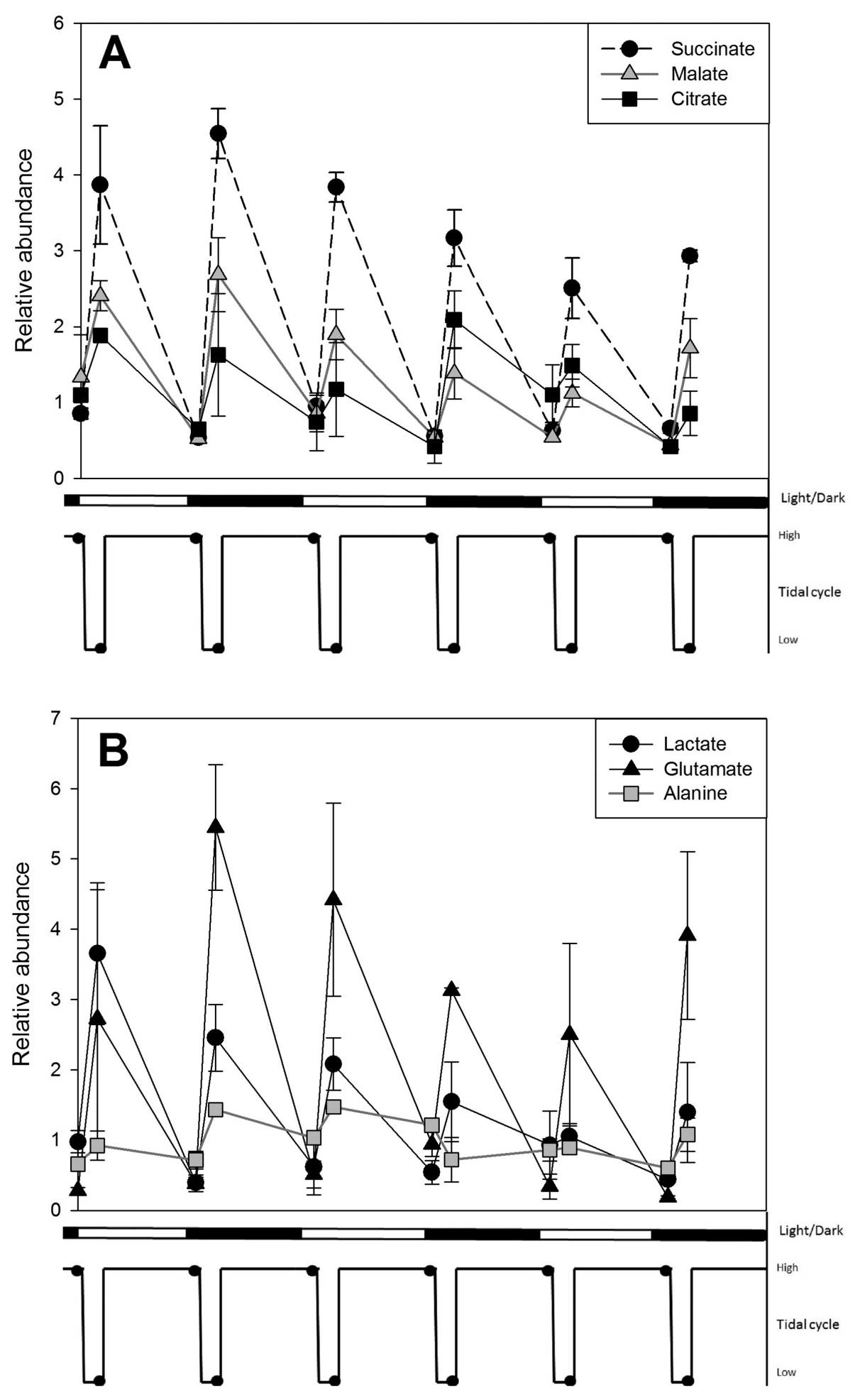

Figure 3 

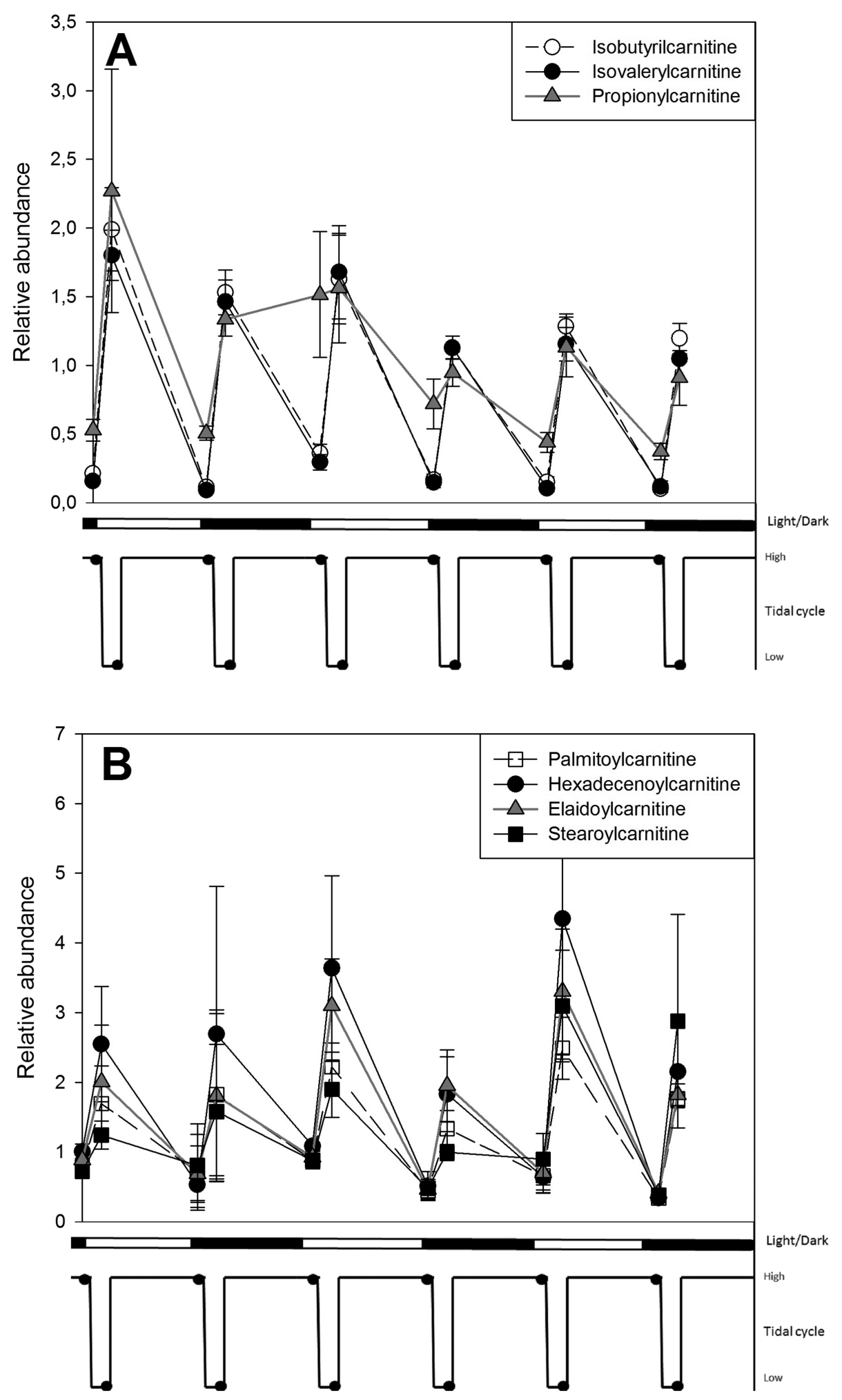

Figure 4 


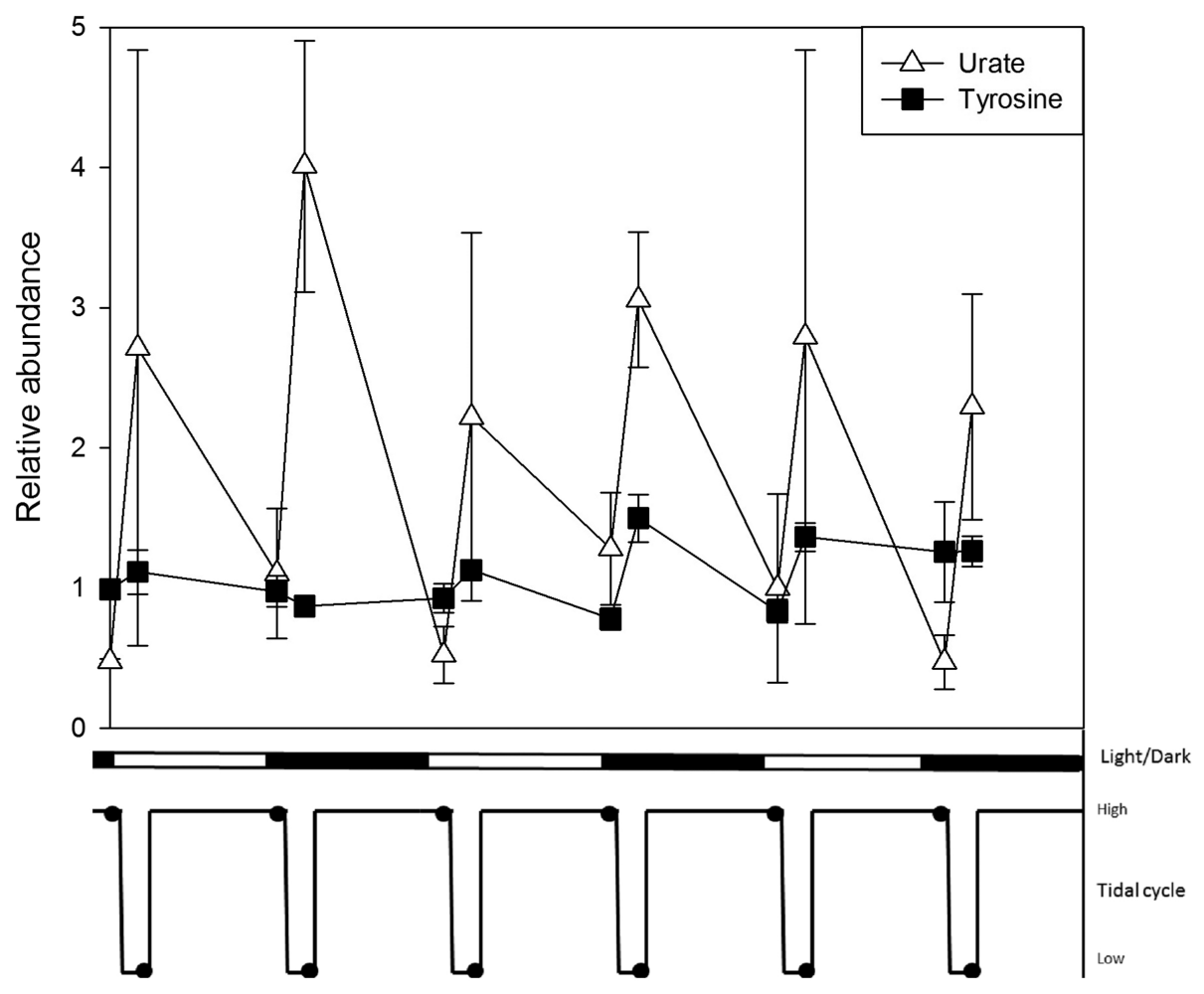

Figure 5 


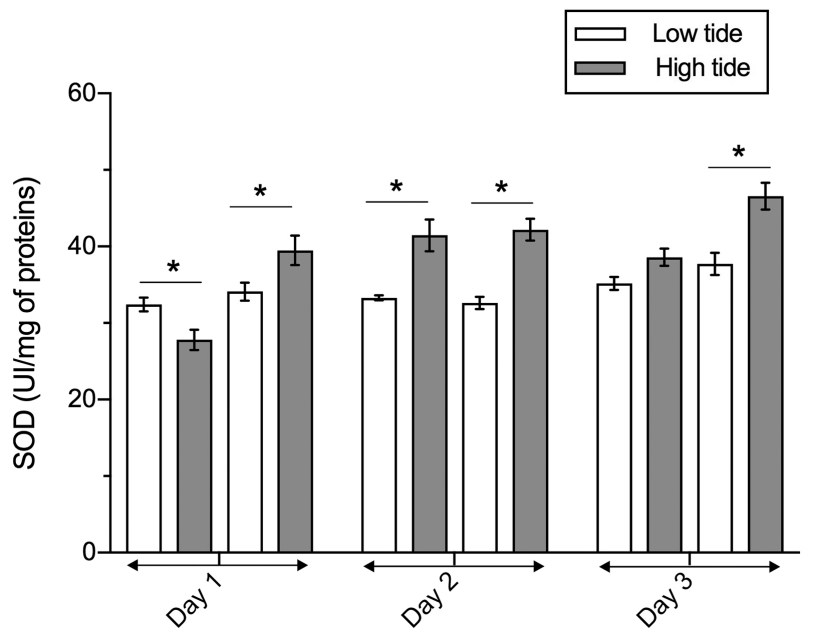

Figure 6 